\title{
EFFECTS OF INTRAVENOUSLY ADMINISTERED \\ SOLUTIONS ON ELECTROLYTES AND ENERGY SUBSTRATES DURING SURGERY*
}

\author{
Emerson A. Moffitt, m.d., † Norbert Schnelle, m.d., Raymond Rodriguez, M.D., \\ Raymond A. LeE, M.D., and Edward S. JUdd, M.D.
}

THERE IS MUCH CONTROversy about which is the most beneficial type of solution for intravenous infusion during general anaesthesia and major operation, and what its volume should be. Probably the most widely used is lactated Ringer's solution $^{1}$ which often is given in large amounts to maintain electrolyte balance and both intravascular and extracellular fluid volumes. A major disadvantage of this solution is that the exogenous lactate does not supply energy as readily as glucose. Without exogenous glucose, the body is forced to mobilize glycogen, lipid, and protein, for the production of adenosine triphosphate (ATP).

To explore the effects of commonly used infusions, we studied three groups of patients who received different solutions and a (control) group to whom none was given, during abdominal operations and for two hours postoperatively. The parameters studied included energy substrates, electrolytes, oxygen concentration in the blood and acid-base variables.

\section{Subjects and Methods}

Each study lasted 3 to $5_{1 / 2}^{1 /}$ hours, including 2 hours postoperatively. The patients had operations for gastrointestinal or gynaecological conditians and appeared otherwise healthy. All were considered grade I or grade II risks according to the classification established by the American Society of Anesthesiology. They werc divided into four groups of roughly comparable age and weight. Those in group I (control) received no infusion; group II received lactated Ringer's solution with 5 per cent dextrose, group III received lactated Ringer's solution only, and group IV received 5 per cent dextrose in water (Table I). All were given slowly at a rate of $300 \mathrm{ml}$ per hour. A $500-\mathrm{ml}$ blood transfusion was given to one patient in group I and to another in group II.

Anaesthesia was induced with thiopentone sodium given intravenously. Succinyl-choline was given for tracheal intubation, and a standard technique was employed for maintenance with nitrous oxide, oxygen, halothane, and tubocurarine chloride.

An arterial blood sample was taken before and after induction of anaesthesia, at midoperation, at the end of operation and 1 and 2 hours postoperatively. The heparinized blood was placed on ice and laboratory processing was begun within

'From the Departments of Anesthesiology and Surgery, Mayo Clinic and Mayo Foundation, Rochester, Minn., U.S.A. This work was supported in part by grant GM 14919 from the National Institutes of Health, Public Health Service.

$\nmid$ Present address: Department of Anaesthesia, Dalhousie University, Halifax, Nova Scotia.

285

Canad. Anaesth. Soc. J., vol. 21, no. 3, May 1974 


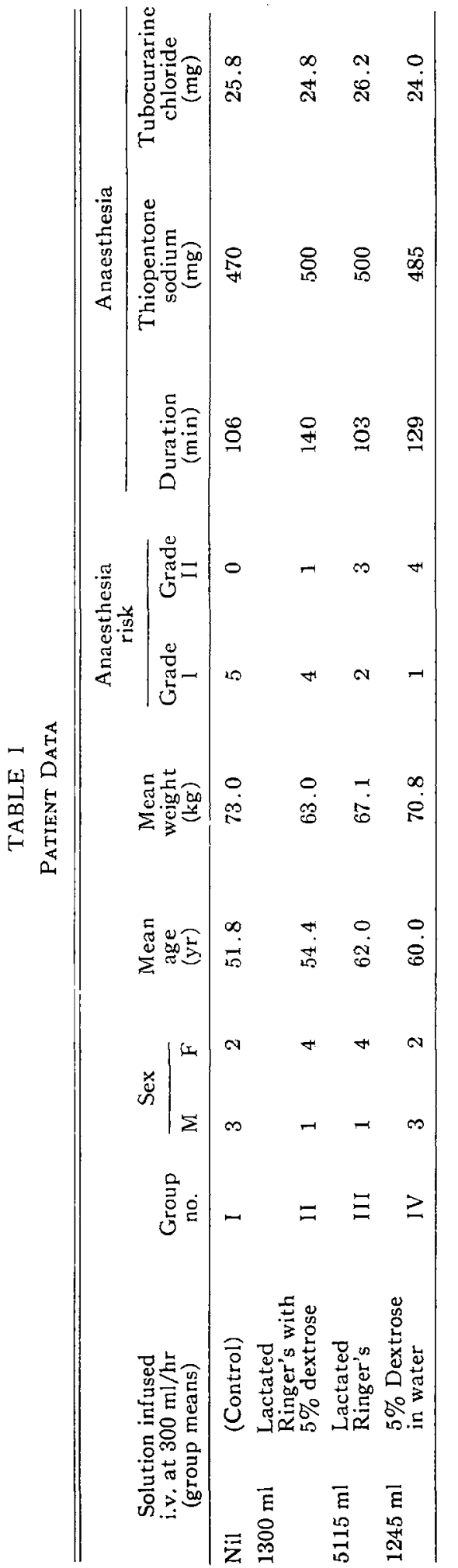


15 minutes. The acid-base balance was determined without correcting the blood gas data for changes in patient temperature. Plasma electrolytes ( $\mathrm{Na}, \mathrm{K}$, and $\mathrm{Ca}$ ), energy substrates (glucose, lactate, pyruvate, nonesterified fatty acids, total ketone bodies), osmolality and hormones (immunoreactive insulin and human growth hormone) were measured by reproducible techniques as previously reported. ${ }^{2,3}$

Paired data in each group were analyzed, comparing later concentrations with the pre-induction (control) values. Unpaired-data analysis was also done, comparing concentrations of variables at each sample time in groups II, III, and IV with those in group I (control). All differences reported are significant at least at the 5 per cent level.

\section{Results}

Arterial blood pressure and pulse rate remained within normal limits throughout the study in all patients. No deleterious effects were detected in the patients who were given no intravenous infusion (control group), in whom the deficit was made up soon after the study.

\section{Blood Gases (Figure 1)}

Arterial oxygen tension was elevated in all groups throughout the operation, due to increased $\mathrm{Fi}_{\mathrm{O} z}$ and controlled ventilation during anaesthesia. The only intergroup acid-base difference was temporary depression of the bicarbonate level immediately after operation in the three treated groups but not in the control group.

\section{Carbohydrate Metabolism (Figure 2)}

In group I, mean glucose concentration was higher at midoperation, through to 1 hour postoperatively, than before induction of anaesthesia. Group I plasma lactate level was elevated above control through the operation and 1 hour afterwards, whereas the pyruvate level was increased throughout. In group II, mean blood glucose was elevated throughout, and plasma lactate and pyruvate levels were raised from midoperation through 1 hour postoperatively. In groups III and IV, glucose levels were elevated at midoperation and increased significantly through 2 hours postoperatively. The mean insulin value increased significantly above control in group IV only, from the end of operation through 2 hours afterwards. In group IV, lactate was increased at the end of operation and 1 hour later, whereas pyruvate was elevated at midoperation and through 2 hours postoperatively.

Compared with group I, group-II patients had higher glucose, lactate and pyruvate levels during operation and at 1 hour postoperatively, while these values for group III showed no significant differences. Group IV showed the greatest comparative differences: mean glucose and pyruvate values were higher than in group I throughout, the lactate value was higher at 1 hour and 2 hours postoperatively, and the insulin level was higher at midoperation and thereafter. 

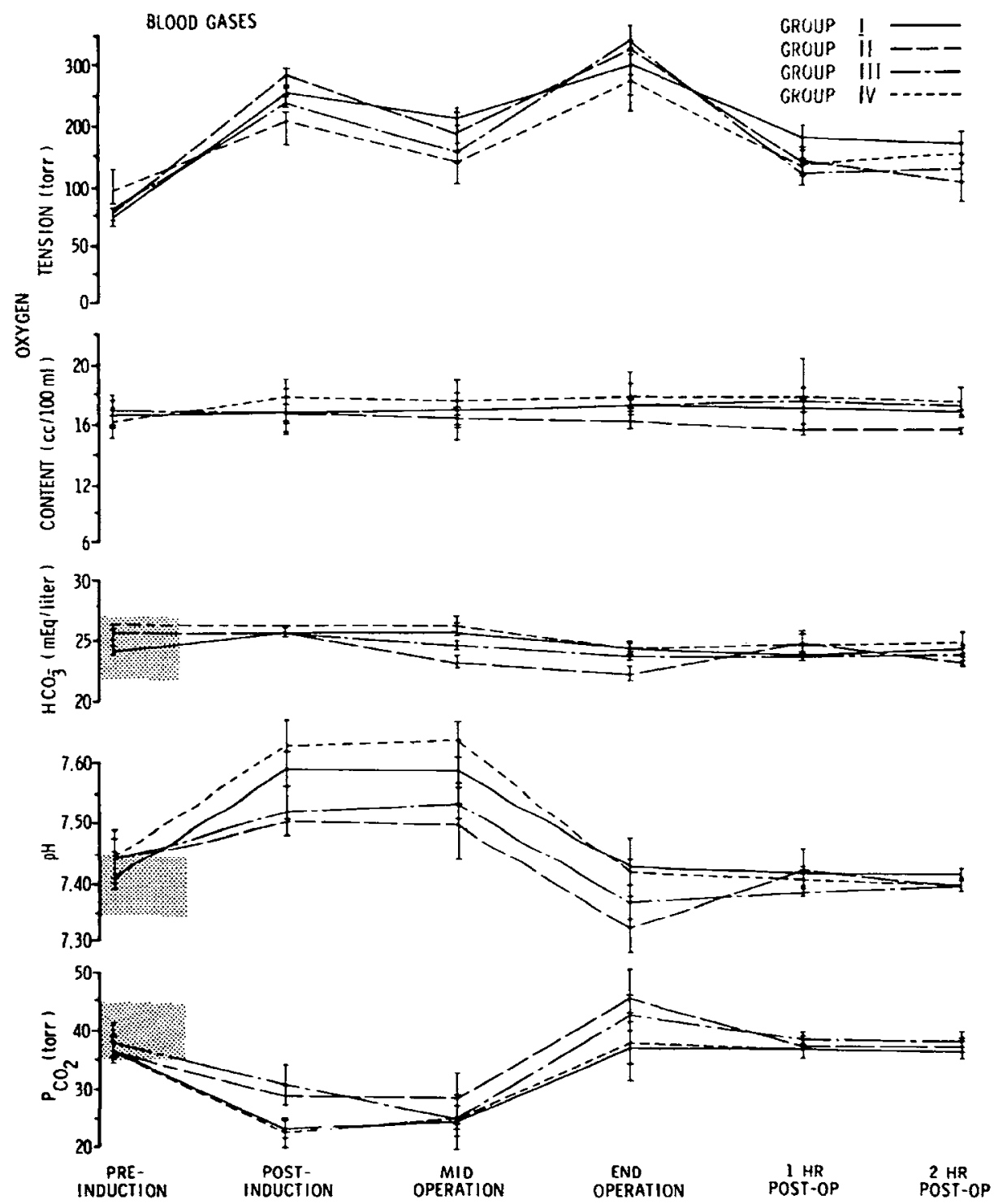

Ficure 1. Mean values of arterial blood gases in four groups of patients: group I (control) were not infused; group II received lactated Ringer's solution with 5 per cent dextrose; group III, lactated Ringer's solution without dextrose; group IV, 5 per cent dextrose in water. The shaded areas indicate normal value ranges.

\section{Lipid Metabolism (Figure 3)}

In groups I and III, mean ketone-body values were elevated above their control values at 2 hours postoperatively. The mean level of nonesterified fatty acids (NEFA) was decreased at midoperation through 1 hour postoperatively in group II, but increased at 1 hour and 2 hours postoperatively in group III. In group IV also, the NEFA level was below control (pre-induction) level at 2 hours postoperatively.

Compared with group I, group II had lower mean levels of NEFA and ketone 

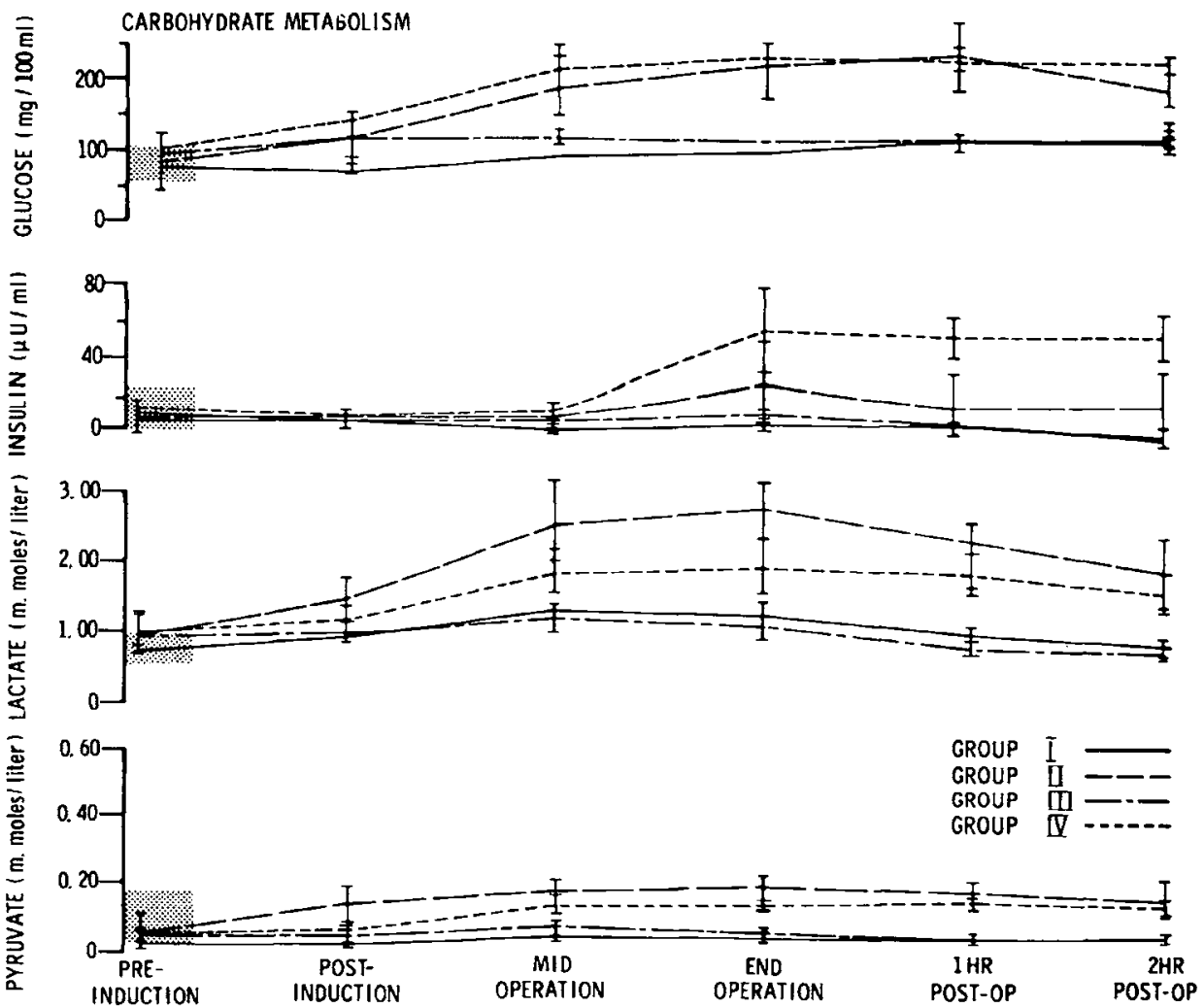

Figure 2. Mean values of blood glucose and of plasma immunoreactive insulin, lactate, and pyruvate, in the four groups of patients (see Figure 1). The shaded areas indicate normal value ranges.

bodies at the end of operation and the latter remained decreased at 1 hour and 2 hours postoperatively. Neither parameter was significantly different from group I in group III, whereas both were lower at 2 hours postoperatively in group IV. Mean values of human growth hormone (HGH) in the three treated groups were not significantly different from the group I value.

\section{Electrolytes (Figure 4)}

No significant changes were detected in group I. In group II plasma osmolality was elevated above control value at the end of operation, whereas the mean plasma sodium value was decreased from after induction through 1 hour postoperatively. In groups II and III the plasma calcium concentration was below the control values at the end of operation and reverted to pre-induction levels thereafter. In group IV, however, the calcium level was decreased at midoperation through 2 hours postoperatively, while plasma sodium values were decreased after induction and in later samples. Mean plasma osmolality was below the lower limit of normal throughout the study in groups I and II, but above the normal range throughout in groups III and IV. (This may indicate a change in the osmometer setting midway through the study.) 


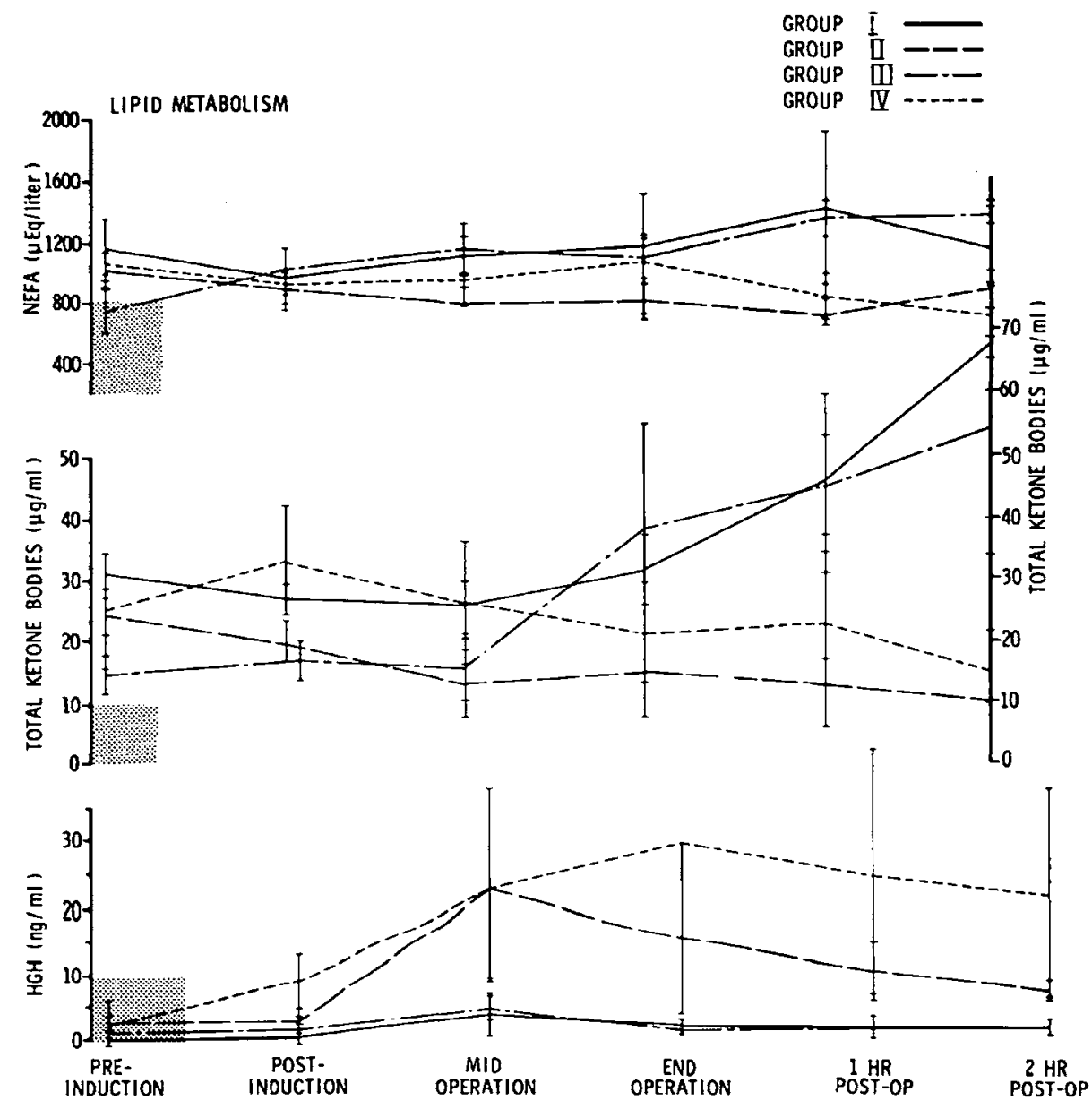

Figure 3. Mean values of plasma nonesterified fatty acids (NEFA), total ketone bodies, and human growth hormone ( $\mathrm{HGH}$ ), in the four groups of patients (see Figure 1). The shaded areas indicate normal value ranges.

Compared with group I, group II had a lower mean plasma sodium level from after induction through 1 hour postoperatively, whereas the mean calcium value was lower only at the end of operation. In group III, the calcium concentration was comparatively lower before induction and through 1 hour postoperatively. In both groups III and IV plasma osmolality was higher than in group I throughout the study. Only one comparative difference in electrolyte levels was detected in group IV: the calcium concentration was lower than in group I at the end of operation and at 1 hour postoperatively. Mean plasma $K$ values in the three treated groups were comparable to those in the control group.

\section{Discussion}

In recent years the main trend in intravenous therapy during and after operation has been to larger amounts, to compensate fully for losses of blood and interstitial fluid. In some cases overenthusiastic replacement therapy has led to fluid overload and water retention in the postoperative period. ${ }^{1}$ 
MOFFITT, et al.: INTRAVENOUSLY ADMINISTERED SOLUTIONS
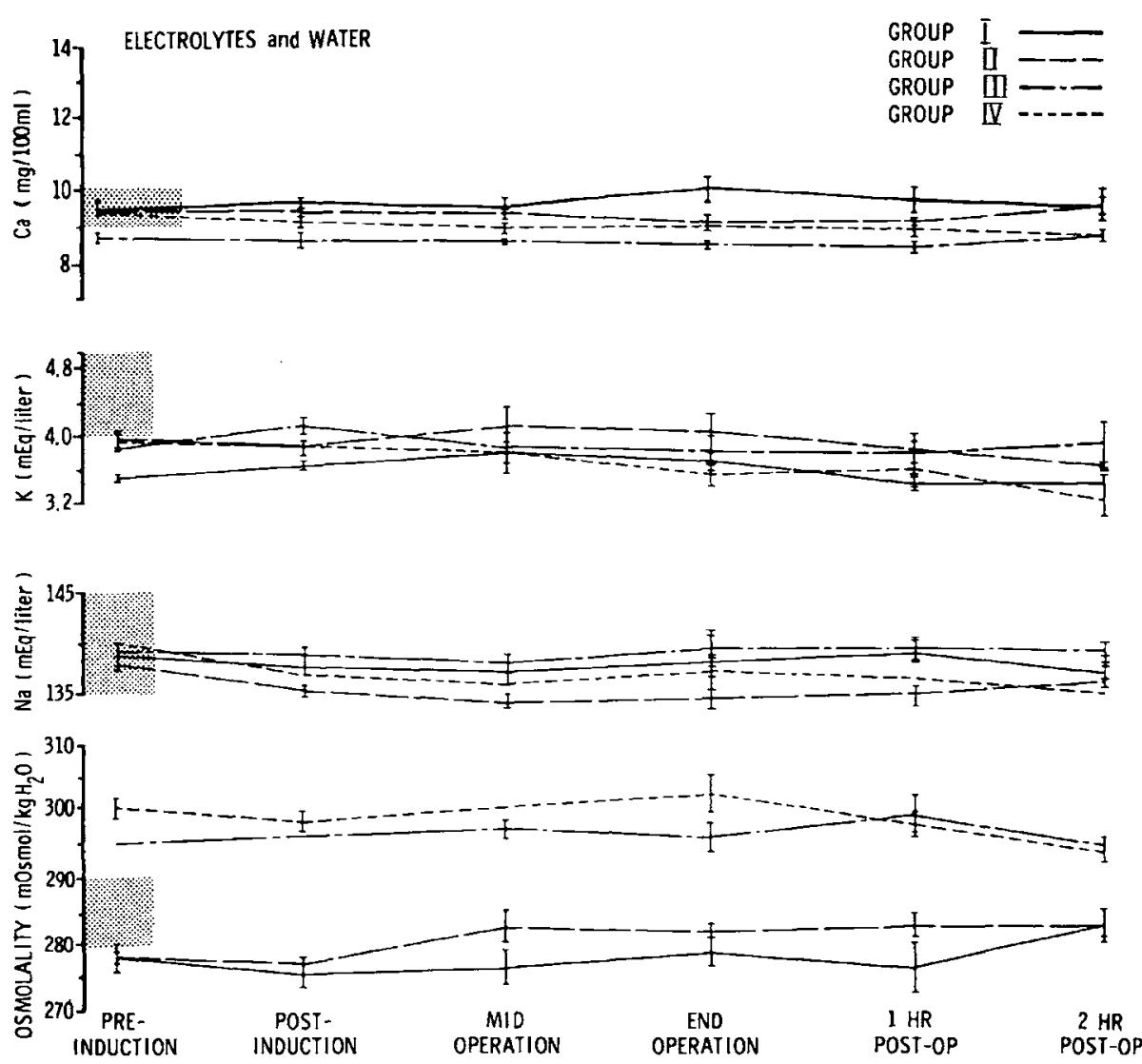

Frgure 4. Mean values of plasma $\mathrm{Ca}, \mathrm{K}$, and $\mathrm{Na}$, and plasma osmolality, in the four groups of patients (see Figure 1). The shaded areas indicate normal value ranges.

Because it has a balanced electrolyte content, lactated Ringer's solution has become the infusion fluid of choice. However, lactate is not a readily available substrate for production of the ATP needed for energy. Lactate, a "metabolic blind alley," is formed anaerobically from pyruvate in the body: it cannot be utilized by any tissue until it has been aerobically oxidized in the liver. The resulting pyruvate then changes to acetyl co-enzyme A, for entry to the Krebs cycle and for the production of ATP. Lactate conversion to glucose also requires ATP, whereas glucose yields ATP as it proceeds through the intermediate steps to become lactate.

Thus, with alterations possible in hepatic blood flow and oxygenation during anaesthesia and major operation, there are sound metabolic reasons for infusing glucose. Without it, the fasting body mobilizes and uses lipids (including fatty acids), glycogen, and protein, in addition to the slower process of metabolizing lactate, to form ATP. The daily administration of $100 \mathrm{~g}$ of glucose to a fasting patient prevents the production of ketone bodies that arise from fatty-acid metabolism. ${ }^{5}$

It was these considerations that led us to examine the effects of lactated Ringer's solution with and without glucose and of 5 per cent glucose in water, during 
and immediately after major operation, and to compare these with the effects of giving no solution (control group). The patients were typical of those in the 40 to 70 year age group who commonly undergo stomach, bowel, and gynaecological operations.

The arterial oxygen content, which reflects the haemoglobin concentration, did not fall significantly. This vindicated our decision to omit blood transfusion in all but two of the patients. Respiratory alkalosis was intentional during anaesthesia, but all three groups of infused patients had a temporarily decreased mean bicarbonate concentration at the end of operation. No other intergroup blood-gas differences were detected.

In patients who received no infusion, the mean electrolyte levels were virtually unchanged but the lack of exogenous energy substrate was evident; thus, their blood glucose increased due to glycogenolysis in the liver, and their rising concentration of ketone bodies during the recovery period reflected increasing lipid utilization. These effects could be due in part to elevated levels of catecholamines in the blood - although the level of $\mathrm{HGH}$, which has similar effects, did not change.

Of the three solutions, which produced least aberration in electrolytes and energy substrates?

There were few changes in electrolyte levels in patients given either the balanced solution or glucose in water without added electrolytes. The predominant changes were decreases in sodium and calcium, apparently indicating haemodilution. As the plasma osmolality governs water movement to and from the intravascular compartment, an intravenous infusion should maintain osmolality of the blood slightly above normal to keep water within the vascular compartment. The normal range of plasma osmolality is $280-290$ mosmoles $/ \mathrm{kg}$ water; thus, 5 per cent dextrose in water ( 265 mosmoles) and lactated Ringer's solution ( 260 mosmoles) are comparably hypo-osmolar. ${ }^{6}$ As every increase of blood glucose of 100 $\mathrm{mg} / 100 \mathrm{mI}$ raises the osmolality 5 mosmoles, ${ }^{7}$ it is evident that lactated Ringer's solution with 50 gms of glucose added should more effectively retain intravascular water.

Patients who received lactated Ringer's solution behaved the same as those who had no infusion, in the sense that bo: hroups resorted to glycogenolysis and lipid mobilization for energy. Fatty-acid and ketone-body levels rose towards the end of the study in these patients, indicating heavy dependence on lipid for energy. Conversely, the patients who received dextrose, in water or in Ringer's solution, appeared to metabolize this substance: their blood glucose and plasma pyruvate and lactate concentrations were higher than in the groups not receiving dextrose, probably due to the greater amount of glucose metabolized. The patients who received 5 per cent dextrose in water, also, had significantly elevated plasma insulin levels. Insulin inhibits lipid mobilization and utilization. This accounts for the lower NEFA and ketone-body levels in the blood during the recovery period in patients given dextrose.

It appears that 5 per cent dextrose solution, given intravenously at $300 \mathrm{ml} / \mathrm{hr}$, is sufficient to increase plasma insulin and to spare lipid during and immediately after operations of the severity and duration studied. Thus, intravenous infusion 
with a solution containing dextrose is beneficial for energy metabolism. Lactated Ringer's solution, which has the added advantage of electrolyte concentrations similar to those in extracellular fluid, is a better vehicle for the glucose than water.

\section{SUMMARY}

The comparative effects of three kinds of intravenous infusion and of no infusion were studied in 20 patients during and after abdominal operation. Plasma concentrations of electrolytes were little different in patients receiving lactated Ringer's solution or 5 per cent dextrose in water at a rate of $300 \mathrm{ml} / \mathrm{hr}$. Patients receiving 5 per cent dextrose, in water or in lactated Ringer's solution, gave evidence of greater glucose metabolism and less lipid utilization than did patients receiving lactated Ringer's or no solution.

\section{RÉSUMÉ}

Sur un groupe de 20 malades, durant et après intervention abdominale, une étude comparative a été faite sur les effets obtenus chez les malades recevant l'un des trois types de solutés (solution de Ringer avec lactate, dextrose 5 pour cent dans l'eau, et dextrose 5 pour cent en solution de Ringer avec lactate) et chez les malades ne recevant aucune infusion. Les concentrations plasmatiques d'électrolytes n'offrirent que peu de différence entre les malades qui recevaient la solution de Ringer avec lactate ou le dextrose 5 pour cent dans l'eau au rythme de $300 \mathrm{ml} /$ heure. Par ailleurs, les malades à qui on administrat du dextrose 5 pour cent, soit dans l'eau soit dans la solution de Ringer avec lactate, firent preuve d'un métabolisme. accentué du glucose et d'une moindre utilisation des lipides que ne le firent les malades recevant la seule solution de Ringer avec lactate ou ne recevant aucun soluté.

\section{REFERENCES}

1. Moore, F.D. \& Shines, G.T. Moderation. Anesth. Analg. 47: 506 (1968).

2. Horrelt, O.H., Tarhan, S., \& Moffitt, E.A. Whole-body metabolism during and after abdominal surgery. Can. Anesth. Soc. J. 16: 525 (1969).

3. Schalch, D.S. \& Parker, M.L. Sensitive double antibody inmunoassay for human growth hormone in plasma. Nature (London) 203: 1141 (1964).

4. White, A., Handler, P., \& Smirh, E.L. Principles of Biochemistry, 4th ed. Toronto, McGraw-Hill (1968), pp. 402-411.

5. Bland, J.H. Clinical metabolism of body water and electrolytes, 1st ed. Philadelphia, Saunders (1963), p. 218.

6. Halden, E.R., II \& Reynolds, B.L. Renal bases for the composition of an extracellular water substitute. Internat. Surg, 58: 85 (1973).

7. Moore, F.D. Metabolic Care of the Surgical Patient. Philadelphia, Saunders (1959), p. 279 . 